\title{
Using VISIR Experiments, Subjects and Students
}

\author{
http://dx.doi.org/10.3991/ijoe.v7iS2.1769
}

\author{
J. Garcia-Zubia ${ }^{1}$, Ingvar Gustavsson ${ }^{2}$, U. Hernandez-Jayo ${ }^{1}$, P. Orduna ${ }^{1}$, I. Angulo ${ }^{1}$, O. Dziabenko ${ }^{1}$, \\ L. Rodriguez ${ }^{1}$, D. Lopez-de-Ipina ${ }^{1}$ \\ ${ }^{1}$ Faculty of Engineering, University of Deusto, Bilbao, Spain \\ ${ }^{2}$ Blekinge Institute of Technology, BTH, Karlskrona, Sweden
}

\begin{abstract}
The paper presents the results of applying the VISIR (Virtual Instrument Systems in Reality) system at the course of analog electronics for various degrees of the Faculty of Engineering of the University of Deusto (Spain). The efficiency of the VISIR had been monitored during past three years. Students' feedback was collected and analyzed. The research shows: 1) VISIR system is functional and useful learning instrument; 2) teacher experience at VISIR plays crucial role in its integration into student experimentation activities; 3 ) students get best knowledge and skills in the analog electronics from combination of experiments at traditional laboratory and remote lab/ VISIR.
\end{abstract}

Index Terms-Remote labs, VISIR consortium, analog electronics.

\section{INTRODUCTION}

VISIR (Virtual Instrument Systems in Reality) is an open laboratory dedicated to remote experimentations at analog electronics. The VISIR is equipped and allows carrying out tasks with real instrumentation. With VISIR the students in front of the computer execute the same job that they would perform at the traditional laboratory: select devices (resistors, capacitors, diodes, etc.), connect them in a breadboard, select and control the instrumentation, and finally, analyze the obtained results. The architecture and characteristics of the VISIR are well described in several papers $[1,2,3]$.

The VISIR system has been implemented by Blekinge Institute of Technology in Sweden and it has been deployed in different Universities worldwide: University of Deusto (Spain), FH Campus Vienna and Carinthia University of Applied Sciences (Austria), Polytechnic Institute of Porto - School of Engineering (Portugal), and India; all of them are members of the VISIR consortium. The main objective of the consortium is to disseminate the benefits of the system, to promote the deployment of more copies of VISIR, and to share experiments and experiences among the members.

\section{SCENARIO}

VISIR is being used in curriculum of the Faculty of Engineering of the University of Deusto since 2007 for different degrees and fields of concentration: Telecommunication, Informatics, Industrial Technologies and Electronics. Presently the subjects related with VISIR are: Digital Electronics, Computer Technology, Analog Electronics, Circuits and Physics.
The scenario of the VISIR system application can be different: (1) at the classroom for illustration of the theory, (2) practice before regular lab sessions, (3) off campus usage, and (4) as a substitute of the traditional laboratory if the educational institution can't provide appropriate equipment.

As an example we will discuss the course Physics for Computer Engineering curriculum. The general objective of this course is to design a logic gate starting with the knowledge of the atomic electron behavior. The syllabus includes: the electron definition, understanding of current, Ohm's law, Direct Current (DC) circuits - resistors, Alternate Current (AC) circuits - capacitors, semiconductors, diode, the AC-DC converter, the MOS (Metal-OxideSemiconductor) transistor, the logic gate, and its characteristics. The students use only VISIR system for experimenting in laboratory.

The applications, assignments, and circuits are:

1. Function generator and oscilloscope. Various input signals are analyzed using an oscilloscope and reading values (see Fig. 1).

2. DC circuits. Basic circuits combining resistors in serial and parallel. Measure of voltage, current and resistor using a tester and a DC power based on Ohm's law (see Fig. 2).

3. AC circuits. Analysis and design of RC circuits, measurement of different values (see Fig. 3).

4. Diode characterization. Modeling of a diode using the DC power and the tester (see Fig. 4).

5. AC circuits. Analysis and design of a basic AC-DC converter: rectifier + filter. Measurement of different values (see Fig. 5).

6. MOS transistor characterization. Modeling of the MOS transistor.

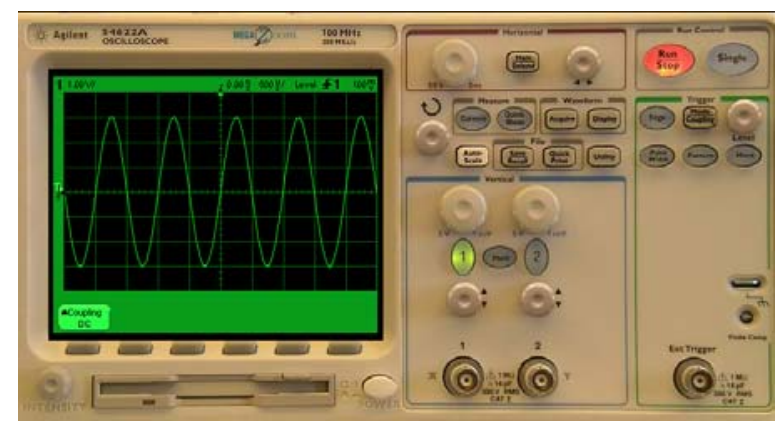

Figure 1. Oscilloscope of the VISIR system 


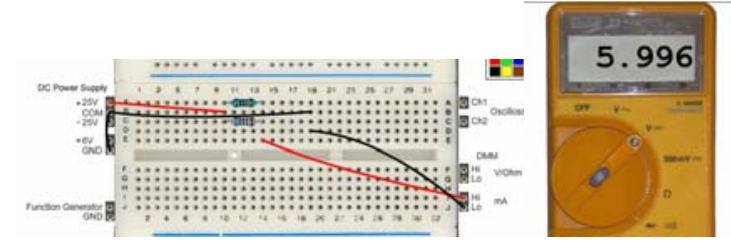

Figure 2. Basic DC circuit and voltage measurement with tester
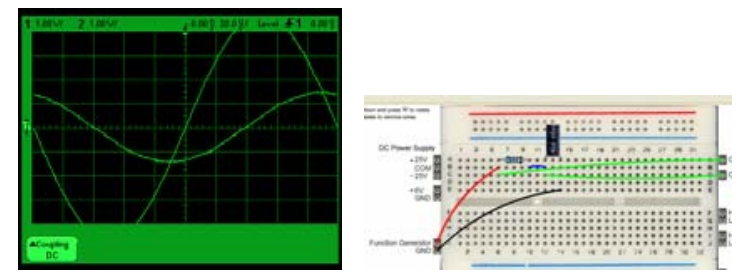

Figure 3.

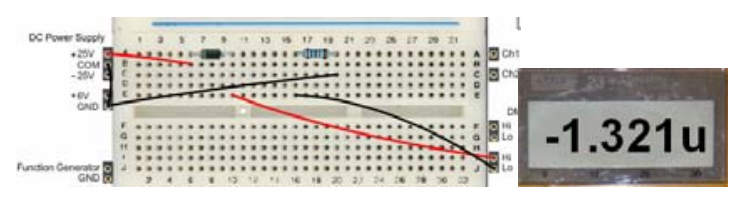

Figure 4. Diode circuit

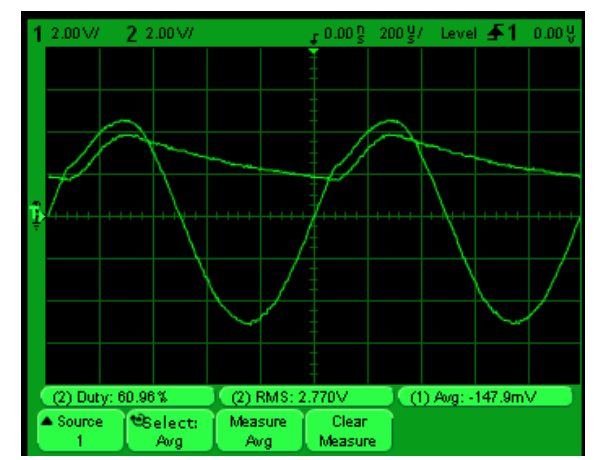

Figure 5. AC-DC converter: oscilloscope and values

\section{STUDENT's OPINION}

In this section we demonstrate the survey filled by the students (see Table I) and the results obtained. The survey is divided in four blocks: Usefulness, Usability, Sense of Reality/Immersion, and Problems. Problems part is not included in the paper. The methodology of the survey has been designed based on results acquired four years ago at University of Deusto [4] and the surveys presented in $[5,6]$.

The students provide answers to the survey questions in the number format where " 5 " points to the complete agreement of the responder with the sentence, and " 1 " points to the complete disagreement. Each colour-line describes the different experience of the teacher/educator with VISIR, see Table II.

The University of Deusto has two campuses: Bilbao and San Sebastian, which is located in about 100 kilometers from Bilbao. On the San Sebastian campus the traditional/real laboratory is unavailable (see Table II, column RealLab). On the Bilbao campus students can use both types of laboratories: traditional and remote/VISIR. The column "Exp." describes the experience of the teachers (see Table II, column Teacher) with remote experiments, and especially with VISIR.
TABLE I.

SURVEY FOR VISIR

USEFULNESS

\begin{tabular}{|l|}
\hline $\begin{array}{l}\text { Q1. WebLab helps me in the subject: concepts, practical exercises, } \\
\text { projects, etc. }\end{array}$ \\
\hline Q3. It is a good idea to extend this WebLab to all the students \\
\hline Q11. I would like to use the WebLab in others subjects \\
\hline Q12. I am satisfied with the WebLab \\
\hline $\begin{array}{l}\text { Q17. I have been motivated by the WebLab to learn more about the } \\
\text { subject }\end{array}$
\end{tabular}

SENSE OF REALITY/IMMERSION

\begin{tabular}{l} 
Q2. Using the WebLab, I feel that it is real and not a simulation \\
\hline Q6. I would like to have a WebCam to see something at the We- \\
bLab: a clock, a device, a screen, etc. \\
Q10. Being far from the VISIR, I have felt myself to be in control of \\
it
\end{tabular}

USABILITY

\begin{tabular}{|l|}
\hline Q4. I have enjoyed using the WebLab \\
\hline Q5. WebLab is easy to use \\
\hline $\begin{array}{l}\text { Q7. The different devices (power supply, multimeter, oscilloscope, } \\
\text { etc) are easy to use }\end{array}$ \\
\hline Q8. I don't have problems with the assigned time \\
\hline Q9. The devices implemented in VISIR are well selected
\end{tabular}

The subjects involved are:

- Computers Technology at Informatics Degree in Bilbao and San Sebastian campuses.

- Digital Electronics at Engineering and Informatics Degrees in Bilbao and San Sebastian campuses.

- Circuits at Engineering Degree in Bilbao campus.

At the first two above subjects the students from Bilbao campus used the traditional and remote laboratories equipment while the students from San Sebastian campus used only the remote laboratory equipment. At the third subject the students used the remote experiments only.

The averages of the surveys are shown in the Table III. The maximum value is 5 , and the minimum value is 1 .

Analyzing the Fig. 6-8 and Table III we obtained the following results:

- The students described the VISIR as a useful tool for the learning. For 1 - 9 scenarios (legend on the Figures 6-8) the student evaluation lays in the range from 3 to 4 .

- The students described VISIR as a tool easy to use (good usability). The values lay in the range from 3 to 4 as well.

- The students showed concern about the sense of immersion of this learning tool. They evaluated this characteristic between 3 and 3,5.

The sense of immersion is related to the usefulness of the VISIR. Therefore, in order to improve the VISIR system the immersion of the user must be augmented. The same results for remote experiments were achieved by Corter, E. et al. [5]. 
TABLE II.

LEGEND’S DESCRIPTION

\begin{tabular}{|c|l|l|l|l|l|l|}
\hline Legend & Teacher & Campus & Subject & Year & Real Lab & Exp \\
\hline 1 & Javier & Bilbao & Comp. Tech. & $08-09$ & Yes & High \\
\hline 2 & Javier & Bilbao & Digital Elect. & $08-09$ & Yes & High \\
\hline 3 & Inaki & Bilbao & Comp. Tech. & $08-09$ & Yes & Low \\
\hline 4 & Inaki & San Seb. & Comp. Tech. & $08-09$ & No & Low \\
\hline 5 & Inaki & San Seb. & Comp. Tech. & $09-10$ & No & Med \\
\hline 6 & Inaki & San Seb. & Digital Elect. & $10-11$ & No & High \\
\hline 7 & Javier & Bilbao & Digital Elect. & $10-11$ & Yes & High \\
\hline 8 & Ignacio & Bilbao & Digital Elect. & $10-11$ & Yes & Med \\
\hline 9 & Imanol & Bilbao & Circuits & $10-11$ & No & Low \\
\hline
\end{tabular}

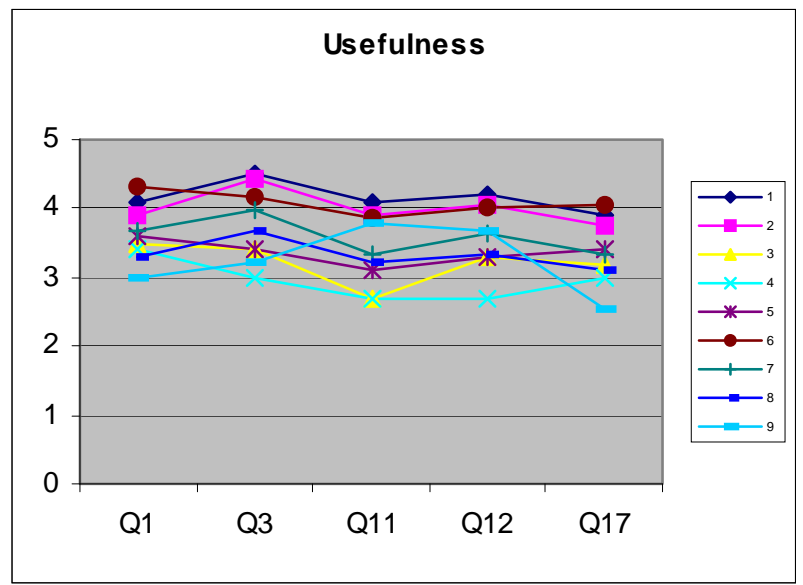

Figure 6. Usefulness (see Table II)

\section{Immersion}

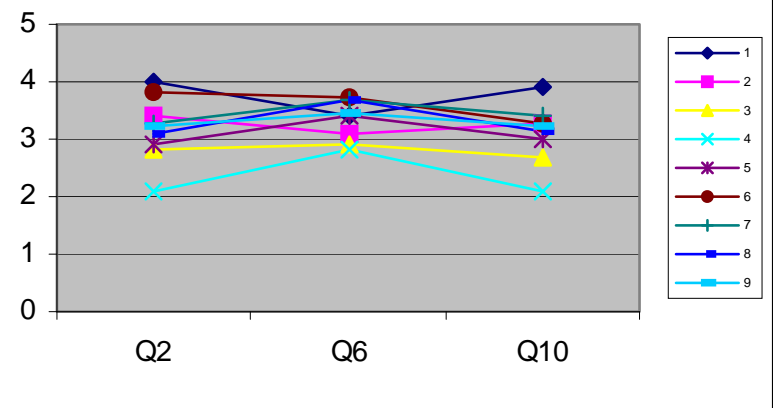

Figure 7. Sense of Reality/Immersion (see Table II)

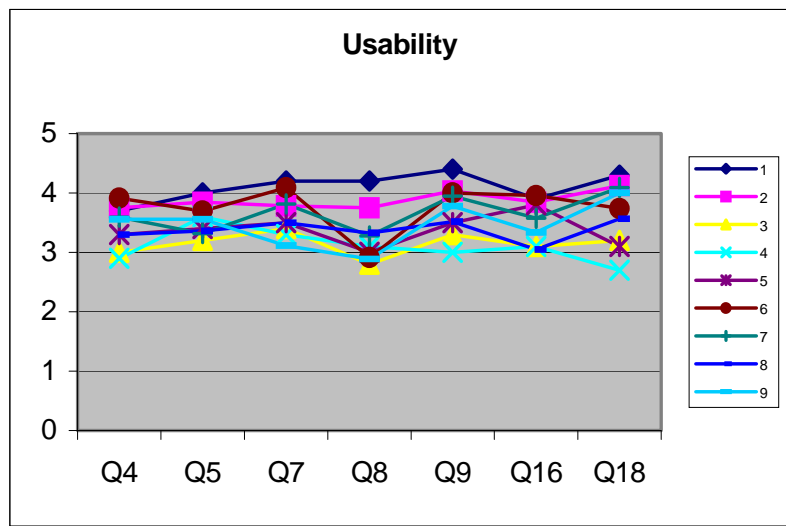

Figure 8. Usability (see Table II)
TABLE III.

SURVEYS' RESULTS

USEFULNESS

\begin{tabular}{|c|c|c|c|c|c|c|c|c|c|}
\hline & 1 & 2 & 3 & 4 & 5 & 6 & 7 & 8 & 9 \\
\hline Q1. & 4,1 & 3,9 & 3,5 & 3,4 & 3,6 & 4,3 & 3,7 & 3,3 & 3,0 \\
\hline Q3. & 4,5 & 4,4 & 3,4 & 3 & 3,4 & 4,2 & 4,0 & 3,7 & 3,3 \\
\hline Q11. & 4,1 & 3,9 & 2,7 & 2,7 & 3,1 & 3,9 & 3,6 & 3,2 & 3,8 \\
\hline Q12. & 4,2 & 4,1 & 3,3 & 2,7 & 3,3 & 4,0 & 3,7 & 3,3 & 3,7 \\
\hline Q17. & 3,9 & 3,8 & 3,2 & 3 & 3,4 & 4,0 & 3,3 & 3,1 & 2,6 \\
\hline
\end{tabular}

SENSE OF REALITY/IMMERSION

\begin{tabular}{|c|c|c|c|c|c|c|c|c|c|}
\hline & 1 & 2 & 3 & 4 & 5 & 6 & 7 & 8 & 9 \\
\hline Q2. & 4 & 3,4 & 2,8 & 2,1 & 2,9 & 3,8 & 3,3 & 3,1 & 3,2 \\
\hline Q6. & 3,4 & 3,1 & 2,9 & 2,8 & 3,4 & 3,7 & 3,7 & 3,7 & 3,4 \\
\hline Q10 & 3,9 & 3,3 & 2,7 & 2,1 & 3,0 & 3,3 & 3,4 & 3,1 & 3,2 \\
\hline
\end{tabular}

USABILITY

\begin{tabular}{|c|c|c|c|c|c|c|c|c|c|}
\hline & 1 & 2 & 3 & 4 & 5 & 6 & 7 & 8 & 9 \\
\hline Q4. & 3,7 & 3,8 & 3 & 2,9 & 3,3 & 3,9 & 3,6 & 3,3 & 3,6 \\
\hline Q5. & 4 & 3,8 & 3,2 & 3,6 & 3,4 & 3,7 & 3,3 & 3,4 & 3,6 \\
\hline Q7. & 4,2 & 3,8 & 3,4 & 3,3 & 3,5 & 4,1 & 3,8 & 3,5 & 3,1 \\
\hline Q8. & 4,2 & 3,8 & 2,8 & 3,1 & 3 & 2,9 & 3,3 & 3,3 & 2,9 \\
\hline Q9. & 4,4 & 4,0 & 3,3 & 3 & 3,5 & 4 & 3,9 & 3,5 & 3,8 \\
\hline
\end{tabular}

The Table IV shows selection of the two most representative questions at the blocks Usefulness, Usability, Sense of Reality/Immersion. The evaluation is organized from the highest to the lowest values. The main results are:

- The students are satisfied with the remote experimentation if the teacher has a broad experience with VISIR system.

- The students' satisfaction grows with the improvement of the teacher knowledge and skills in the remote/VISIR experiments.

- There is a high probability that the next semester students' evaluation and satisfaction of the remote laboratories for the teachers of scenarios 8 and 9 will be higher since their experience will be improved.

- Usually, the students are more positive in using remote laboratory if they have experimented at a traditional lab environment. This conclusion is not true for the case-scenario 6.

Attending [5] it is interesting to evaluate the correlations among the different questions of the survey. Figure 9 shows the main correlations among Usefulness (Q1 and Q11), Sense of Reality/Immersion (Q2 and Q10) and Usability (Q4 and Q5).

The highest correlations are found between Q1-Q2 and Q1-Q4:

- Q1. WebLab helps me in the subject: concepts, practical exercises, projects, etc. USEFULNESS.

- Q4. I have enjoyed using the WebLab. USABILITY.

- Q2. Using the WebLab, I feel that it is real and not a simulation. SENSE of IMMERSION. 
TABLE IV.

ORDERED SURVEY

USEFULNESS

\begin{tabular}{|c|c|c|c|c|c|c|c|c|c|}
\hline & 1 & 6 & 2 & 7 & 5 & 9 & 8 & 3 & 4 \\
\hline Q1. & 4,1 & 4,3 & 3,9 & 3,7 & 3,6 & 3,0 & 3,3 & 3,5 & 3,4 \\
\hline Q11. & 4,1 & 3,9 & 3,9 & 3,6 & 3,1 & 3,8 & 3,2 & 2,7 & 2,7 \\
\hline
\end{tabular}

SENSE OF REALITY/IMMERSION

\begin{tabular}{|c|c|c|c|c|c|c|c|c|c|}
\hline & 1 & 6 & 2 & 7 & 5 & 9 & 8 & 3 & 4 \\
\hline Q2. & 4 & 3,8 & 3,4 & 3,3 & 3,2 & 3,1 & 2,9 & 2,8 & 2,1 \\
\hline Q10. & 3,9 & 3,3 & 3,3 & 3,4 & 3,2 & 3,1 & 3,0 & 2,7 & 2,1 \\
\hline
\end{tabular}

USABILITY

\begin{tabular}{|c|c|c|c|c|c|c|c|c|c|}
\hline & 1 & 6 & 2 & 7 & 5 & 9 & 8 & 3 & 4 \\
\hline Q4. & 3,7 & 3,9 & 3,8 & 3,6 & 3,6 & 3,3 & 3,3 & 3 & 2,9 \\
\hline Q5. & 4 & 3,7 & 3,8 & 3,6 & 3,3 & 3,4 & 3,4 & 3,2 & 3,6 \\
\hline
\end{tabular}

$\begin{array}{rrrrrr} & 2 & 4 & 5 & 10 & 11 \\ 1 & \mathbf{0 , 6 7} & \mathbf{0 , 7 4} & 0,49 & 0,03 & 0,53 \\ 2 & & 0,36 & 0,19 & 0,12 & 0,26 \\ 4 & & & 0,25 & 0,13 & 0,47 \\ 5 & & & & -0,36 & 0,23 \\ 10 & & & & & 0,01 \\ 11 & & & & & \end{array}$

Figure 8. Correlations among Q1, Q2, Q4, Q5, Q10 and Q11

It can be said that for improving the Usefulness of VISIR it is important to augment in the user the sense of reality when he is using the VISIR interface. This conclusion is totally in line with the prediction of [5]. A deeper statistical analysis must be done.

\section{CONCLUSIONS AND FUTURE WORK}

In this paper we present the results of survey held during last three years. The research shows: 1) VISIR system is a functional and useful learning instrument; 2) teacher experience at VISIR plays the crucial role in its integration into student experimentation activities; 3) attending the correlations of Figure 9, the sense of immersion of the remote experiments should be improved; 4) best knowledge and skills at analog electronics students get from combination of experiments at traditional laboratory and remote lab/ VISIR.

The future research and development with VISIR at the University of Deusto will be focused on:

- Integrating VISIR for more courses, disciplines and degrees.

- Engaging the teachers, professional trainers, and educators for using remote experiments in their curriculum.
- Providing comprehensive training and support for teachers, educators, and trainers to build their competences in the remote experimentation.

- Improving the sense of immersion of the students when they are using the VISIR.

- Designing and implementing an automatic assessment system using VISIR for evaluation with remote experimentation.

- Implementing VISIR in a cloud computer network in order to share experiments with other universities and education institutions in efficient way.

- Collaborating with VISIR consortium for dissemination and deployment of the tool worldwide

\section{REFERENCES}

[1] Gustavsson et al (2009) "On objectives of instructional laboratories, individual assessment, and use of collaborative remote laboratories”, IEEE Transactions on Learning Technologies, TLT, VOL. 2, No 4. (2009)

[2] I. Gustavsson, J. Zackrisson, K. Nilsson, J. Garcia-Zubia, L. Håkansson, I. Claesson, and T. Lagö, "A Flexible Electronics Laboratory with Local and Remote Workbenches in a Grid," International Journal of Online Engineering (iJOE), vol. 4, n. ${ }^{\circ}$ 2, pp. 12-16, 2008.

[3] OpenLabs Electronics Laboratory, "Teachers's guide to the VISIR online laboratory for electrical experiments", https://openlabs.bth.se/electronics/index.php?page=AboutPage\# (accessed Feb.1, 2011)

[4] J. García-Zubia, D. López-de-Ipiña, P. Orduña, U. Hernández, I. Angulo, J. Irurzun. Acceptance, usability and usefulness of WebLab-Deusto from students point of view. Third Conference on Digital Information Management, 2008. ICDIM 2008. Pages 899904. ISBN: 978-1-4244-2916-5. Nov. 2008.

[5] Corter, E. et al (2007). “Constructing Reality: A Study of Remote, Hands-On, and Simulated Laboratories”. ACM Transactions on Computer-Human Interaction, Vol. 14, No. 2. (2007)

[6] Lang, D.,et al (2007) "Pedagogical evaluation of remote laboratories in eMerge project”, European Journal of Engineering Education, 32:1, pp 57 - 72. (2007). http://dx.doi.org/10.1080/0304379 $\underline{0601055626}$

\section{AUTHORS}

J. García-Zubía and I. Angulo are with the University of Deusto, Avd. Universidades 24, 48007, Bilbao, Spain (email: zubia, ignacio.angulo@deusto.es).

I. Gustavsson, is with the Blekinge Institute of Thchnology, Department of Electrical Engineering, Karlskrona, 37179, Sweden, (email: ingvar.gustavsson@ bth.se).

U. Hernández, D. López, P. Orduna, O. Dziabenko are with the Deusto Research Institute, Avd. Universidades 24, 48007, Bilbao, Spain (email: unai.hernandez, pablo.orduna, olga.dziabenko,dipina@deusto.es).

This article is an extended version of a paper presented at the International Conference on Remote Engineering \& Virtual Instrumentation (REV2011), held at Transylvania University, Brasov, Romania, June 28 July 1, 2011. Received 28 July 2011. Published as resubmitted by the authors 28 September 2011. 